\title{
The effectiveness of basic life support training on nursing students' knowledge and basic life support practices: a non-randomized quasi-experimental design
}

\author{
Selmin Kose ${ }^{1}$, Semiha Akin², Onur Mendi ${ }^{3}$, Sonay Goktas ${ }^{2}$
}

1. Biruni University Faculty of Health Sciences Nursing Department Protokol Yolu No:45, 10.Y1l Cd., 34010 Zeytinburnu/Istanbul.

2. University of Health Sciences, Faculty of Nursing. Mekteb-i T1bbiye-i Şahane, Selimiye Mah. Tibbiye

Cad. No:38, 34668 Üsküdar/Istanbul

3. Istanbul Bilim University Distance Education Training Center Yazarlar Sokak No:17 34394 Esentepe Sisli, Istanbul/Turkey

\section{Emails:}

selminkose@yahoo.com; semihaakin@yahoo.com; mendico@gmail.com; baltacisonay@hotmail.com

\begin{abstract}
Background: Provision of up-to-date information and skills training related to basic life support practices is very important for nursing students' professional development and practitioner and education related roles.

Objective: The purpose of the study was to examine the effectiveness of basic life support training on knowledge and practices among nursing students.

Methods: A non-randomized quasi-experimental design (one group pre-test-post-test) was used in this study. The study was conducted in the laboratory of an undergraduate nursing school. The sample consisted of a convenience sample of $1^{\text {st }}$-year students enrolled in the undergraduate nursing class. The study sample consisted of 65 nursing students. Basic life support training included both theoretical and practical components. The students' knowledge and practices were assessed before basic life support training. Data were collected using the knowledge assessment questionnaire. The practical skills for basic life support were observed and assessed using a checklist. The pre- and post-assessment practice scores were compared.

Results: After basic life support training, level of knowledge and practical skill scores were higher compared to pre-training scores $(\mathrm{t}=-12.442, \mathrm{p}=0.000 ; \mathrm{t}=-22.899, \mathrm{p}=0.000)$. There was a significant and moderate association between the adult basic life support knowledge form scores and the adult basic life support practice assessment form scores obtained after the training ( $\mathrm{r}$ $=0.39, \mathrm{p}<0.01)$.

Conclusion: The study showed that basic life support training improved kmowhedge and skills related to basic life support practices in nursing students. Periodic basic life support training is very importy for competency in this area among nursing students.

Keywords: Basic life support, training, nursing, stexdents

DOI: https://doi.org/10.4314/ahs.v20i2.53

Cite as: Kose S, Akin S, Mendi O, Goktas S. The effectipenes of basic life support training on nursing students' knowledge and basic life support practices: a non-randomized quasi-experimental design. Afri Health Sci. 2020; 20(2): 966-976. bttps:/ / doi.org/10.4314/ abs.v20i2.53
\end{abstract}

\section{Corresponding author:}

Semiha Akin,

University of Health Sciences, Faculty of Nursing.

Mekteb-i Tibbiye-i Şahane, Selimiye Mah. Tıbbiye

Cad. No: 38, 34668 Üsküdar/Istanbul

Telephone: 021641896 16-2317

Email address: semihaakin@yahoo.com

\section{Introduction}

Cardiac diseases are among the leading causes of death worldwide. The sudden cardiac arrest requires emergency interventions that increasingly occurs in all age groups. ${ }^{1}$ Life-saving interventions are vital for the prevention of sudden cardiac arrest associated deaths. ${ }^{2}$ Successful cardiopulmonary resuscitation is the first step for returning to life in people experiencing cardiac arrest. Successful

(C) 2020 Kose S et al. Licensee African Health Sciences. This is an Open Access article distributed under the terms of the Creative commons Attribution License (https:// creativecommons.org/licenses/BY/4.0), which permits unrestricted use, distribution, and reproduction in any medium, provided the original work is properly cited. 
cardiopulmonary resuscitation at the scene by health team members plays a role in reducing mortality rates related to cardiac arrest. ${ }^{3}$

The American Heart Association emphasizes the need to gain competency regarding cardiopulmonary resuscitation practices in health team members in order to reduce the rate of sudden cardiac arrests. ${ }^{4}$ However, theoretical education alone is not sufficient for applying a successful cardiopulmonary resuscitation. In order to successfully apply cardiopulmonary resuscitation, current knowledge should be updated, technical skills should be consolidated, and sufficient self-esteem related to the application should be established in accordance with training and manual guidelines prepared for the health teap.

Nurses are expected to provide effective emergency aid services. Nurses may encounter various emergency cases such as sudden cardiac arrest within the units they work in and in settings outside the hospital. In these emergency scenarios, nurses have to be the first to practice basic life support. Nurses successfully applying first aid and basic life support steps in acute conditions may positively affect morbidity and mortality rates related to cardiac arrest. Nurses possessing excellent knowledge and skills about basic life support practice would significantly influence the outcome of advanced life support practices.

Provision of up-to-date information and skills training related to basic life support practices in nursing education programs is very important for nursing students' professional development and practitioner and education related roles. In addition, nurses have important roles and responsibilities in terms of informing the society on current basic life support practices. Previous studies showed that nursing students' level of knowledge on basic life support needs to be improved. ${ }^{5-7}$ Nursing students learn basic theoretical knowledge and gain basic skills about basic life support during nursing education. However, skills training on basic life support practices may be insufficient. Nursing students with inadequate skills on basic life support practices may experience anxiety and a lack of self-esteem related to this practice. Training on basic life support increase nursing students' knowledge and provide that they implement evidence-based basic life support practices. Previous studies demonstrated that basic life support training significantly improved nursing students' knowledge, practice skills, attitudes, and self-efficacy. ${ }^{5,6-11}$ Also, training on basic life support would increase nurses' self-esteem related to basic life support practices and contribute to anxiety management. Provision of both theoretical and applied training on basic life support and periodical repetition and update of this training is important for improving students' knowledge and skills in this area. The purpose of the study was to examine the effectiveness of basic life support training on the knowledge and practices of nursing students.

\section{Research hypothesis}

Basiclife support training improves the knowledge of par ing students about basic life support.

Basic life support training improves the basic life support practices and skills of nursing students.

\section{Methods \\ Study design}

A non-randomized quasi-experimental design (One group pre-test-post-test) was used in this study. This design examined the effectiveness of basic life support training on the knowledge and practices of nursing students. The study was conducted in the laboratory of an undergraduatenursing school between November 1 and December 30 of the year 2016.

\section{Sample size and study participants}

The study population comprised of first-year nursing students enrolled in the bachelor's degree program. All firstyear nursing students who were willing to participate in the study and those who did not get any training on basic life support at school were invited to the study. A convenience sample of $1^{\text {st }}$-year nursing students enrolled in the Bachelor's Degree program was included in the study.

Calculation of research sample size: Power analysis using the $G^{*}$ Power (v3.1.9) program was conducted in order to determine the sample size. A 5-unit difference between pre- and post-training BLS scores was accepted as the minimum difference indicating clinical significance. At the beginning of the study, the standard deviation of change was determined as 9.52 units based on data obtained from 10 people. According to this, the minimum sample size needed to be 50 at the level of $\alpha=0.05$ with $95 \%$ power. Considering the possibility of drop-outs during the study, the sample size was enhanced by $20 \%$ and thus the minimum sample size was calculated as 60 . The total number of $1^{\text {st }}$-class undergraduate nursing students was 74. Two students did not fill out the post-train- 
ing assessment questionnaires. Five students were not at the school during training days. Four students were not willing to participate in the study. The sample consisted of 65 nursing students.

The study was conducted on first-class students because at this first-year the students did not get a course at school about Basic Life Support. At the second-year, the students get BLS training and first aid course. For the third course, the students have a chance to improve their knowledge and practical skills about pediatric BLS training and first aid. Therefore, the nursing students' knowledge and practical skills about BLS can be influenced both by the school courses at second and thirdyear courses, and the current BLS training. We did not evaluate the retention aspect of the current BLS training at the second-year or third-year students, because the assessment of retention would not provide a definite yesult of the effect of current BLS training.

\section{Ethical considerations}

Ethical committee permission was obtained to conduct the research. Institutional permission was granted from the nursing school administration. The researchers explained the aim and procedures of the current research to the students. Nursing students gave written informed consent. The participants were asked to complete and return the questionnaires. Their confidentiality was guaranteed.

\section{Data collection}

Researchers prepared the assessment tools. Before the implementation of the tool, it was tested in a pilot study. The pilot study revealed that the tool was easy to use and applicable. Three assessment questionnaires were used to collect data.

Both adult basic life support knowledge questionnaire and adult basic life support observation checklist were prepared by the researchers. The expert group was asked to review both questionnaires. The expert group consisted of four nursing academicians and/or specialists in Basic Life Support practices. Each member of the expert group was asked to review and rate the relevance of each item using a four-point rating scale ranging from 1 (not at all important) to 4 (very important). The experts' ratings were calculated. The content validity index (CVI) score was computed by summing the percentage agreement scores of all items that were given by the experts a rating of ' 3 ' or ' 4 '.12 CVI of the adult basic life support knowledge questionnaire was $96 \%$ and adult basic life support observation checklist was $98 \%$. Later, both questionnaires pre-tested on 10 nursing students and they were found to be easy to understand.

In order to mitigate the bias, the raters were calibrated in a pilot study of 10 students. The observation results of both raters were compared. Based on small differences within observations, raters were trained about the observation process and necessary feedback was provided. There were no statistical differences between the ratings of both observers. Inter-rater reliability was assessed using the intra-class correlation coefficient (ICC).

1. Student Information Form: It included questions about age, gender, marital status, a history of receiving any first-aid training prior to nursing education, experience in basic life support practices, and history of withessing bo sid life support practices.

2. Adul Basic Life Support Knowledge Questionnatre: This form included 35 questions about knowledge and practices on basic life support, primary and secondary patient/injured assessment, calling the health institution, precautions related to the scene, emergency aid numbers, and criteria for terminating first-aid interventions. Adult Basic Life Support Knowledge Questionnaire included 5 multiple-choice questions and 10 true/false questions. Correct answers were rated 1 point, and incorrect answerswere rated 0 points. The minimum score that can be obtained from the questionnaire was 0 , the maximum score was 35. Higher knowledge questionnaire scores indicated the better knowledge about basic life support practices.

\section{Adult Basic Life Support Observation Check-} list: This checklist included 14 steps related to basic life support practices. The checklist was filled out by the researcher and has 3-Likert type response categories. Basic life support practice steps are marked as "sufficient", "partially sufficient" or "insufficient" by the administrator. The response "sufficient" receives 1 point, "partially sufficient" receives 2 points, and "insufficient" receives 3 points. The minimum score is 14 and the maximum score is 42. Lower scores indicate that better skills about basic life support practices.

\section{Procedure}

Data collection process was shown in Figure 1. The students were informed about the study. First-year students who were available and who met the inclusion criteria made up the study sample (convenience sampling). The sample size was calculated as 60 subjects. A total of 65 nursing students were included in the study sample. Written informed consent was obtained from each student.

African Health Sciences Vol 20 Issue 2, June, 2020 


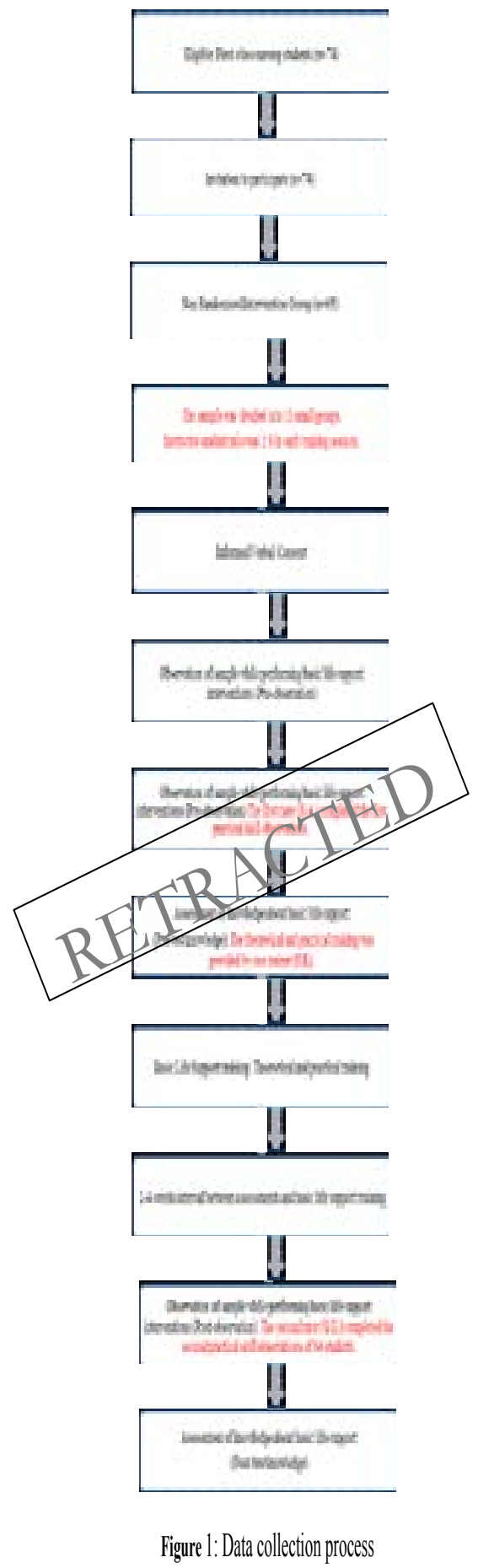

In order to provide more effective training, the sample was divided into three groups. Each group included 22 students. In order to prevent any bias, the theoretical and practical training was provided by one trainer (S.K). The trainer (S.K) has been certified and experienced in basic life support training. Instructor-student ratio was 1:22 in each training session. The trainer (S.K) provided the same theoretical and practical training to one group of students in a day. Each student group has received the theoretical training in the mornings and a practical training in the afternoons.

Two raters were used for the practical skill observations of nursing students. The first rater (S.A.) completed the first practical skill observations of 66 students before the theoretical education (first-observation before Basic Life Support training). The second rater (S.G.) completed the second practical skill observations of 66 students after the theoretical education (post-observation after Basic Life Support training). 
1. Pre-test assessment: The students were asked to fill out the Adult Basic Life Support Knowledge Questionnaire.

2. Pre-observation: Each student was asked to perform every step of basic life support in order before attending the Training Program for Basic Life Support. The trainer assessed the students' practical skills during students' demonstration of each step of basic life support practice on a model using the Adult Basic Life Support Observation Checklist.

3. Training: The training program for basic life support was developed by the researchers. Basic life support training included both theoretical and practical components

a) Theoretical training: The duration of theole te training was 120 minutes. The teaching Rethed of the first section was lecture and discussion. Whe student sample was divided into three groups.

b) Practical training: The second section of the training included practical training on basic life support. Within the context of the practical training program, the trainer demonstrated each step of basic life support practices. Afterward, each student was asked to perform every step of basic life support in order. The practical training was repeated until the students could successfully perform every step of basic life support.

4. Post-test assessment: The participants were asked to fill out Adult Basic Life Support Knowledge Questionnaire following the training program for the second time. Adult Basic Life Support Knowledge Questionnaire was completed 2 weeks or a maximum of 4 weeks after the training.
5. Post-observation: Following the completion of the training program, each student was asked to perform every step of basic life support in order on a model following the Training for Basic Life Support. The trainer assessed the students' practice skills during students' demonstration of each step of basic life support on a model using the Adult Basic Life Support Observation Checklist.

\section{Statistical analysis}

A pover ahalysis using the $G^{*}$ Power (v3.1.9) program yas domducted in order to determine the sample size. Statistical analyses were carried out using the SPSS 16.0 (Statistical Program for Social Sciences) software. Pre-test and post-test assessment scores were compared using the Paired-Samples t-test. Mann-Whitney U test was used to compare personal characteristics. The possible associations between age and questionnaire scores were tested using Spearman's rank correlation coefficient. Statistical significance (p) level was set at $<0.05$. The inter-rater intraclass correlation coefficient (ICC) was found 0.776 for pilot observations.

\section{Results}

\section{Personal characteristics}

The mean age of the sample was 19.54 (SD: 2.21) and $81.5 \%$ of the students were female. The majority of students reported that they did not receive any first-aid training $(69.2 \%)$ and BLS $(73.8 \%)$ in the past. One-fourth of the sample $(24.6 \%)$ reported to witnessing a basic life support at least once in their life (Table 1).

Table 1: Personal characteristics of nursing students $(\mathrm{N}=65)$

\begin{tabular}{|c|c|c|c|}
\hline Variables & & $\mathrm{n}$ & $\%$ \\
\hline Age & $19.54 \pm 2.21$ (Range: $18-27)$ & & \\
\hline \multirow[t]{2}{*}{ Gender } & Female & 53 & 81.5 \\
\hline & Male & 12 & 18.5 \\
\hline \multirow[t]{2}{*}{ Marital status } & Married & 1 & 1.5 \\
\hline & Single & 64 & 98.5 \\
\hline \multirow[t]{2}{*}{ The history of first aid training in the past } & Yes & 20 & 30.8 \\
\hline & No & 45 & 69.2 \\
\hline The history of previous training about Basic Life & Yes, received & 17 & 26.2 \\
\hline Support & No, not received & 48 & 73.8 \\
\hline Setting where past Basic Life Support training was & Driving license course & 3 & 4.5 \\
\hline \multirow[t]{2}{*}{ provided } & During clinical practice at the hospital & 1 & 1.5 \\
\hline & School & 13 & 20 \\
\hline \multirow[t]{2}{*}{ Status of applying Basic Life Support } & Yes & 5 & 7.7 \\
\hline & No & 60 & 92.3 \\
\hline \multirow[t]{2}{*}{ Status of witnessing Basic Life Support practice } & Yes & 16 & 24.6 \\
\hline & No & 49 & 75.4 \\
\hline \multirow[t]{2}{*}{ Having a driver's license } & Yes & 16 & 24.6 \\
\hline & No & 49 & 75.4 \\
\hline \multirow[t]{2}{*}{ Vocational nursing - school graduates } & Yes & 14 & 21.5 \\
\hline & No & 51 & 78.5 \\
\hline
\end{tabular}


Knowledge and practice skills about adult basic life support

Correct answers to knowledge questionnaire before and after basic life support training were shown in Table 2. The rates of correct answers of nursing students after basic life support training and questionnaire scores were very high. Following basic life support training, percentages related to the competency of basic life support skills and mean scores were also very high (Table 2 and Table 3).

Table 2: Correct answers are given to the Adult Basic Life Support Knowledge Questionnaire before and after the training and comparison of pre- and post-training scores $(\mathrm{N}=65)$

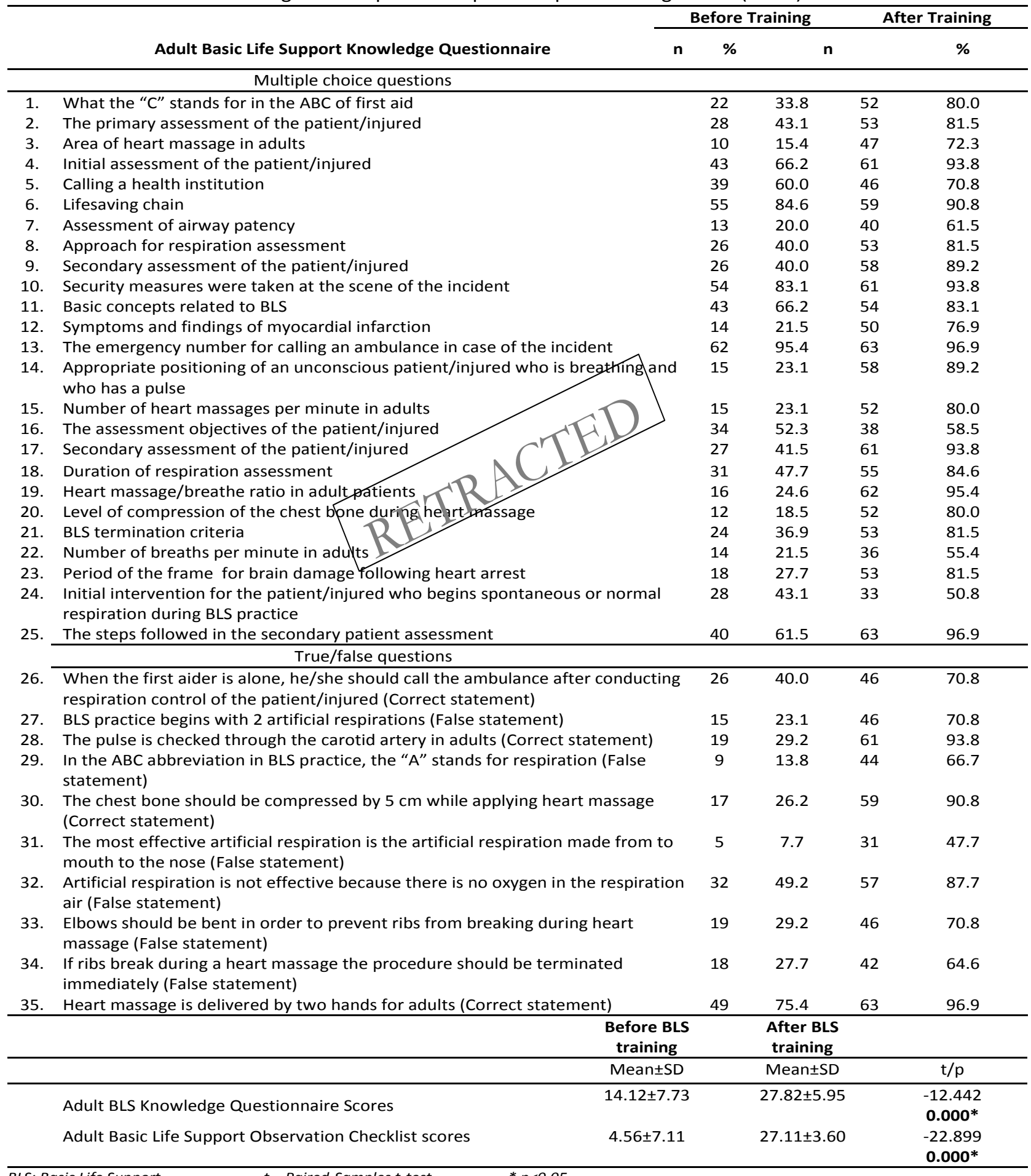




\begin{tabular}{|c|c|c|c|c|c|c|}
\hline & \multicolumn{3}{|c|}{ Before Badic L te Support Tralning } & \multicolumn{3}{|c|}{ After basle Ufe Support Tniving } \\
\hline & Insufficient & $\begin{array}{l}\text { Partioly } \\
\text { sutficken }\end{array}$ & Sufficient & Mcuffident & $\begin{array}{l}\text { Partivi } \\
\text { affident }\end{array}$ & Sulficiert \\
\hline & $\leqslant$ & $\$$ & $\leq$ & $\$$ & $s$ & $\$$ \\
\hline Aduit Easc LA Support & & & & & & \\
\hline 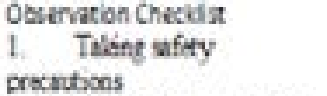 & BA 6 & 15 & 138 & 15 & 15 & 938 \\
\hline $\begin{array}{l}\text { 2. Identfyers onesd and } \\
\text { olturrimy perminsaon for help }\end{array}$ & 90.8 & $\cdot$ & 92 & 15 & - & 95.4 \\
\hline $\begin{array}{l}\text { 3. Assessing the level of } \\
\text { the gubert'senseias }\end{array}$ & 76.9 & 3.1 & 200 & 15 & * & 95.4 \\
\hline $\begin{array}{l}\text { 4. Calling tur national } \\
\text { emergencyaneber }\end{array}$ & 58.5 & 10.8 & & & 15 & 93.8 \\
\hline $\begin{array}{l}\text { 5. Avissing te ureide of } \\
\text { the mooth }\end{array}$ & 892 & & & & $3:$ & 923 \\
\hline 6. Opering airuzys & & & & 15 & 92 & 86.2 \\
\hline $\begin{array}{l}\text { 7. Cheling the sans } \\
\text { rexpiabion }\end{array}$ & & & 13.8 & 15 & 3.1 & 92.3 \\
\hline $\begin{array}{l}\text { 8. Chrckang the patent's } \\
\text { pulse }\end{array}$ & & 215 & 15.4 & 15 & $\cdot$ & 95.4 \\
\hline 9. Inisixing hart massage & 831 & 31 & 13.8 & 15 & $\cdot$ & is. 4 \\
\hline $\begin{array}{l}\text { 10. Finfing the beart } \\
\text { masisate bea }\end{array}$ & 92.3 & 15 & 62 & 15 & 7.7 & 87.8 \\
\hline 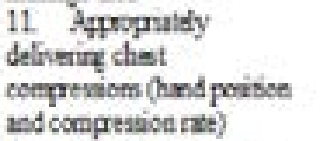 & 81.5 & 3.1 & 15.4 & 15 & 6.2 & 89.2 \\
\hline $\begin{array}{l}12 \text { Aqpiyms } 2 \text { athicial } \\
\text { tergubor }\end{array}$ & 81.5 & 25 & 16.9 & 31 & . & 93.8 \\
\hline $\begin{array}{l}\text { 13. Positoring if the patien } \\
\text { is uxconcious and cortinue to } \\
\text { breate properly }\end{array}$ & 831 & 15 & 15.4 & 15 & 15 & 938 \\
\hline 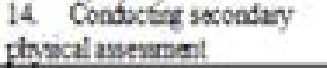 & 96.9 & -2 & 31 & 15 & 6.2 & 89.2 \\
\hline
\end{tabular}

There was a statistically significant difference between pre- and post-training knowledge scores $(\mathrm{p}<0.05)$. Post-training knowledge scores were significantly higher than pre-training knowledge scores $(\mathrm{t}=-12.442$, $\mathrm{p}=0.000)$. There was a statistically significant difference between pre- and post-training skill scores $(\mathrm{p}<0.05)$. Post-training skill scores significantly increased compared to pre-training skill scores $(\mathrm{t}=-22.899, \mathrm{p}=0.000)$ (Table 2). This finding indicated that basic life support training improved knowledge and practical skills related to basic life support.

Adult Basic Life Support Observation Checklist scores and Adult Basic Life Support Knowledge Questionnaire scores were compared. There was a statistically significant and moderate association between pre-training Adult Basic Life Support Knowledge Questionnaire scores and the Adult Basic Life Support Observation Checklist scores $(\mathrm{rs}=0.52, \mathrm{p}<0.01)$. This finding indicated that there is a relationship between basic life support knowledge and practical skills among nursing students. There was a statistically significant and moderate association between post-training Adult Basic Life Support Knowledge Questionnaire and the Adult Basic Life SupportObservation Checklist $(\mathrm{rs}=0.39, \mathrm{p}<0.01)$.

\section{Variables associated with the knowledge about adult basic life support and practice skills}

There was a statistically weak association between the pre-training mean Adult Basic Life Support Knowledge Questionnaire score and age ( $\mathrm{rs}=-0.25, \mathrm{p}=0.042)$. The analysis did not reveal a significant association between post-training Adult Basic Life Support Observation Checklist score and age ( $p>0.05)$.

There was a significant but weak association between the pre-training Adult Basic Life Support Observation Checklist scores and age ( $r s=-0.25, p=0.048)$. There was no significant association between the post-training basic life support skills and age $(\mathrm{p}>0.05)$. 
The mean pre-training Adult Basic Life Support Knowledge Questionnaire scores were compared with personal characteristics of the students. Pre-training Adult Basic Life Support Knowledge Questionnaire scores showed significant differences with regard to the history of receiving first-aid training or basic life support training, experience in performing basic life support, a history of witnessing basic life support and education level $(p<0.05)$. Nursing students who reported to obtain first aid or basic life support training in the past, who reported a history of performing basic life support and witnessing a basic life support and those who were vocational nursing school graduates had significantly higher pre-training Adult Basic Life Support Knowledge Questionnaire scores.

The pre-training Adult Basic Life Support Observation Checklist scores were compared with students' personal characteristics (Table 4). The pre-training Adult Basic Life Support Observation Checklist scores showed significant differences according to the history of receiving BLS training, experience in BLS practices, and who were vocational nursing school graduates $(p<0.05)$. Nursing students who reported to obtain basic life support training in the past, reported previously to perform basic life support, and who graduated from health high school had significantly higher pre-training Adult Basic Life Support

Table 4: Comparison of pre- and post-training Adult Basic Life Support Knowledge Questionnaire and Basic Life Support Observation Checklist scores according to personal characteristics ( $N=65)$

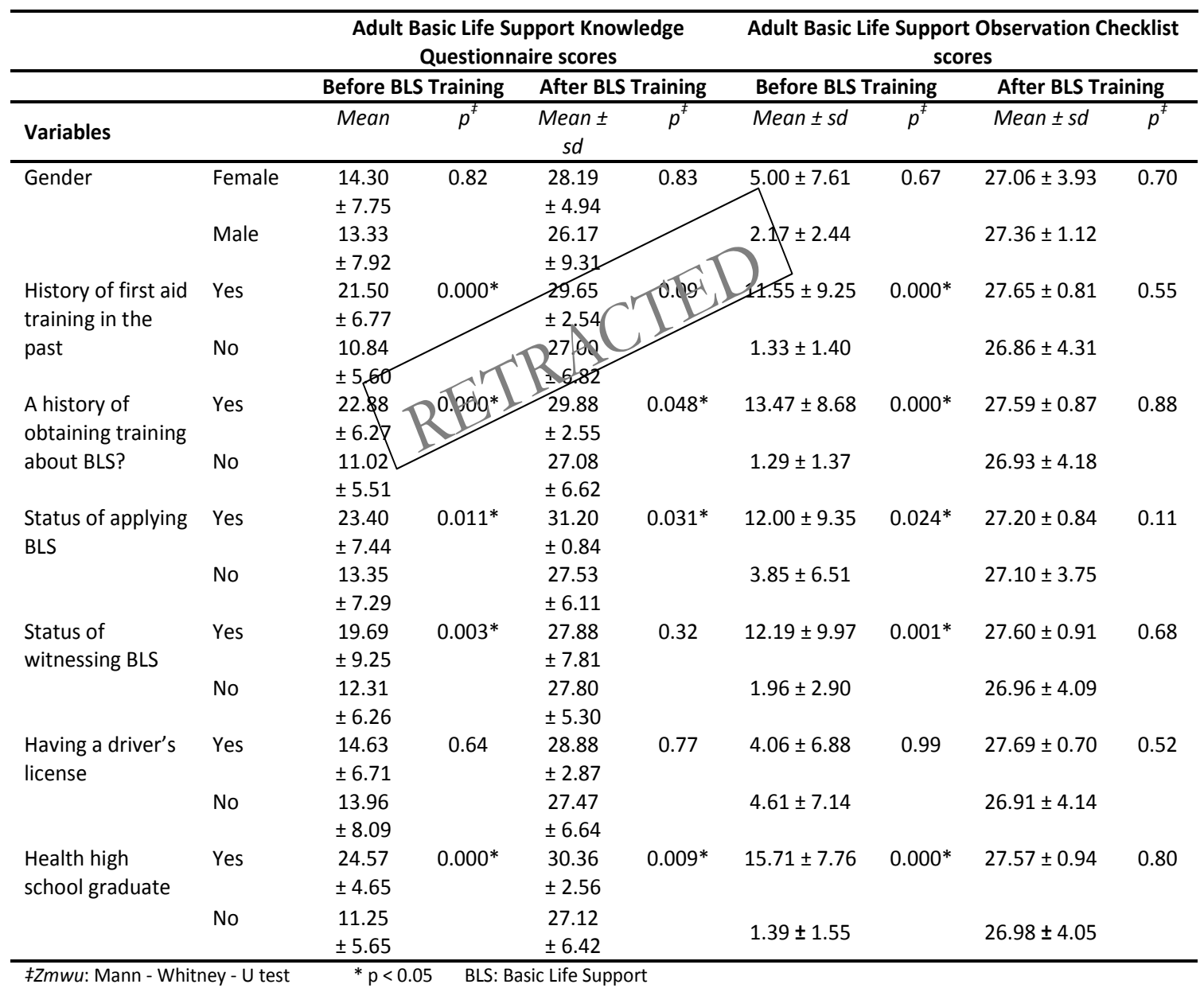

\section{Observation checklist scores.}

The post-training Adult Basic Life Support Observation Checklist scores were compared with students' personal characteristics. Significant differences were detected between post-training Adult Basic Life Support Observation Checklist scores with regard to the history of receiv- ing first-aid or basic life support training, who reported to perform basic life support practices, and with a history of witnessing basic life support, and who were vocational nursing school graduates $(\mathrm{p}<0.05)$.

The nursing students who reported to obtain basic life support training in the past, who previously performed 
basic life support, and who were vocational nursing school graduates had significantly higher post-training Basic Life Support Knowledge Questionnaire scores. The post-training Adult Basic Life Support Observation Checklist scores did not differ with regard to students' personal characteristics $(\mathrm{p}>0.05)$.

\section{Discussion}

Basic professional knowledge and skills of nursing students are affected by many factors such as theoretical training provided during nursing education, laboratory work, practical training, personal experiences, and clinical observations. In addition to this, use of up-to-date education methods and basing training on evidence-based practice are of crucial importance in terms of nursing education outputs. The current study was conducted in order to evaluate the effect of BLS training on knowledge and practical skills of nursing students. Students' knowledge of BLS was examined using the knowledge form before the training, while BLS practice skills were assessed using an observation forms. In the present study t? study revealed that first year nursing student phad insufficient knowledge and practice skills related to BLS prior to the training. Considering that the sample included only first-year students, it was expected that these students would have insufficient levels of knowledge and practice skills related to BLS. The number of studies conducted with undergraduate nursing students is rapidly increasing. Many studies reported that nursing students have insufficient levels of knowledge and practice skills related to BLS. $., 7,10,13$

One of the unique characteristics of the current about the study is the highlights made within the education. The theoretical education was constructed based on the update version of 2017 AHA Guidelines for CPR on Adult. ${ }^{14}$ In order to provide more effective training, the sample was divided into small groups. The available research reported that the nursing student' knowledge and skills for BLS steps improved considerably following the educational intervention. , $, 9,10,15-19$ The current study differed from the other studies with respect to research design (using before-and-after-design), sample characteristics of nursing student sample, dividing the research sample into small groups, outcome assessment methods.

It is very important for the success of theoretical and practical training to provide BLS training for groups in appropriate size using valid methods in accordance with international and national guidelines. In the current study, theoretical and practical training was delivered to the students after initial observation and pre-test assessment. After a minimum of 2 weeks and a maximum of 4 weeks following theoretical training, knowledge assessment was repeated (post-test). In the study, a significant difference between pre- and post-training Adult BLS Knowledge scores were found. This finding indicates that the theoretical training on Adult BLS was very effective. Knowledge scores after the training showed a 2-fold increase. In the literature, it was reported that training delivered to small groups had a more positive effect on nursing students' BLS practice skills. ${ }^{20}$ The high increase can be explained bythe fact that the Adult BLS training was conducted with small groups and certain aspects of the training were repeated using specific teaching methods in the present study.

Studies conflacted with nursing students compared prend oost-training BLS knowledge levels, psychomotor skills, and self-efficacy. These studies showed that following BLS training, knowledge on BLS practice, psychomotor skills, and self-efficacy significantly increased. .,9-11,21,22 $^{-1}$ Other studies reported that following BLS training, nursing students had increased skills related to BLS practice. ${ }^{8,23}$ The rate of correct answers given by the students on the knowledge questionnaire (percentage values) was very high, however, the findings indicate that the level of knowledge in certain areas can be further improved. Students' level of knowledge on airway patency assessment, spontaneous respiratory features, rescue breathing practices, patient/injured assessment objectives, and seeking emergency aid in particular needs to be improved. Periodic repetition of BLS training would increase the persistence of the training and develop students' skills. Thus, in a study conducted with nursing students, it was reported that periodic repetition of BLS training positively affected self-esteem. ${ }^{24}$

After theoretical training, BLS steps were demonstrated for the students using a cardiopulmonary resuscitation model. Afterward, the students were asked to practice BLS steps in order on the cardiopulmonary resuscitation model. The practice continued until students correctly applied every BLS step. After a minimum of 2 weeks and a maximum of 4 weeks following practical training, nursing students were asked to practice BLS steps in order on the cardiopulmonary resuscitation model. An in- 
dependent observer assessed students' BLS skills during this second assessment. In the present study, the BLS practice assessment scores obtained before and after the Adult BLS training were compared. It was determined that post-training assessment scores increased 5-fold compared to pre-training scores.

\section{Strengths and limitations}

The instructor (SK) was specialized in and certified for providing basic life support training. Two separate researchers observed the students during the first and second observation. First aid training and other life support training begin in the second year of nursing education. Therefore, the sample was made of first-year nursing students alone. There was no control group. The intervention group was formed using non-randomized techniques. The current study did not assess the retention level for basic life support knowledge and practices. The unique characteristics of their methods of teaching BLS as compared to the existing methods are as follows:

- The training at the current research has been given by experienced researcher with the Certificate of Education of the First Aid Trainer approved by the Ministaty Health-Turkey.

- In order to provide more effective trining, the sample was divided into three small

- The instructor gave the students enough time to ask questions about Basic Life Support education. The instructor provided sufficient time for the students to practice the BLS steps with participants until they gain skills on the models.

- The trainers used at the up to date guidelines for the education of Basic Life Support steps.

- In order to prevent any bias, the theoretical and practical training was provided by one trainer (S.K). apart from the trainer, additionally two raters were used for the practical skill observations of nursing students. The first rater (S.A.) completed the first practical skill observations of 66 students before the theoretical education (first-observation before Basic Life Support training). The second rater (S.B.) completed the second practical skill observations of 66 students after the theoretical education (post-observation after Basic Life Support training).

- $\quad$ Each student was asked to apply Basic Life Support on mannequins by giving a separate scenario.

- In order to mitigate the bias, the raters were calibrated in a pilot study of students.

- In order to prevent any bias and interaction among students, each student was asked to apply Basic Life Support steps in a training room alone, not letting students attend the practice session. The students completed the Adult Basic Life Support Knowledge Questionnaire unaided.

\section{Conclusion}

The current study showed that BLS training improved knowledge and practice skills related to BLS in nursing students. Training on BLS practice will positively affect students' self-esteem and self-efficacy. It is recommended to repeat BLS training throughout nursing education in order to increase the effectiveness of BLS practices during clinical training and real-life situations.

\section{Acknowledgements}

We express our gratitude and appreciation to the nursing students.

\section{Conflict of interest}

The arthorgeteclare no conflict of interest.

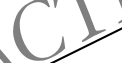

\section{References}

1. Uslu Y, Korkmaz FD. Kardiyopulmoner resüsitasyon sonrası hasta yönetimi [Patient management after cardiopulmonary resuscitation]. Turkish Journal of Cardiovascular Nursing. 2015; 6(10):99-111.

2. T.C. Sağlık Bakanlığı Türkiye Kalp ve Damar Hastalıkları Önleme ve Kontrol Program 2015-2020 [Ministry of Health Turkish Cardiovascular Disease Prevention and Control Program 2015-2020]. Anıl Reklam Matbaa Ltd. Şti., Ankara, 2015.

3. Perkins GD, Handley AJ, Koster RW, Castrén M, Smyth MA, Olasveengen, T., Monsieurs KG, Raffay V, Gräsner JT, Wenzel V, Ristagno G, Soar J, Adult basic life support and automated external defibrillation section Collaborators. European Resuscitation Council Guidelines for Resuscitation 2015: Section 2. Adult basic life support and automated external defibrillation. Resuscitation. 2015; 95:81-99.

4. Neumar RW, Shuster M, Callaway CW, Gent LM, Atkins DL, Bhanji F, Brooks SC, de Caen AR, Donnino MW, Ferrer JM., Kleinman ME, Kronick SL, Lavonas EJ, Link MS, Mancini ME, Morrison LJ, O'Connor RE, Samson RA, Schexnayder SM, Singletary EM, Sinz EH, Travers AH, Wyckoff MH, Hazinski MF. Part 1: Executive Summary 2015 American Heart Association Guidelines update for cardiopulmonary resuscitation and emer- 
gency cardiovascular care. Circulation. 2015; 132 (18 Suppl 2):S315-67.

5. Dal U, Sarpkaya D. Knowledge and psychomotor skills of nursing students in North Cyprus in the area of cardiopulmonary resuscitation. Pakistan Journal of Medical Sciences. 2013; 29(4):966-71.

6. Partiprajak S, Thongpo P. Retention of basic life support knowledge, self-efficacy and chest compression performance in Thai undergraduate nursing students. Nurse Education in Practice. 2016;16(1):235-41.

7. Vural M, Koşar MF, Kerimoğlu O, Kızkapan F, Kahyaoğlu S, Tuğrul S, İşleyen HB. Cardiopulmonary resuscitation knowledge among nursing students: A Questionnaire study. Anatolian Journal of Cardiology. 2017; 17(2):140-5.

8. Abdollahi AA, Yazdi KH, Hosseini SA, Khoddam H. Effect of station training method on students' cardiopulmonary resuscitation activity. Iranian Journal of Critical Care Nursing. 2010; 3(3):105-108.

9. Goswami R, Kanika Sembian N. Effectiveness of the training program on knowledge and practices regarding Basic Life Support (BLS) among nursing students. Nurse Education Today. 2006; 26(3):218-27.

11. Park G. The Effect of basic cardiopulmonary resuscitation training on cardiopulmonary resuscitation knowTedge, attitude, and self-efficacy of nursing students. A.t. vanced Science and Technology Letters (Healthoare ind Nursing). 2015; 116:56-60.

12.Pierce AG. Measurement. In Principles and Practice of Nursing Research ed. Talbot LA ed. Mosby, St Louis, 1995, pp. 265-291.

13. Chandrasekaran S, Kumar S, Bhat SA, Saravanakumar Shabbir PM, Chandrasekaran V. Awareness of basic life support among medical, dental, nursing students and doctors. Indian Journal of Anaesthesia. 2010; 54(2):121-6.

14.American Heart Association 2017; Focused Updates on Adult and Pediatric Basic Life Support and Cardiopulmonary Resuscitation Quality, https://eccguidelines. heart.org/wp-content/uploads/2017/11/2017-Focused-Updates_Highlights.pdf

15.Kipsang J, Bruce JC. A comparison of cardiopulmonary resuscitation between two groups of advanced practice student nurses at a medical training college in Kenya. Africa Journal of Nursing and Midwifery. 2011; 13(2):103118.
16.Josipovic, P, Webb, M and McGrath, I. 'Basic life support knowledge of undergraduate nursing and chiropractic students', Australian Journal of Advanced Nursing. 2009; 26(4):58-63.

17.Tobase L, Peres HHC, Tomazini EAS, Teodoro SV, Ramos MB, Polastri TF. Basic life support: evaluation of learning using simulation and immediate feedback devices. Rev. Latino-Enfermagem. 2017; 2:e2942.

18.Terzi B, Polat Ş, Düzkaya DS. Evaluation of basic life support training program provided for nurses in a university hospital. International Journal of Medical Research. 2017; 6(6):70-76.

19.Tobase L, Peres HHC, Gianotto-Oliveira R, Smith N, Polastri TF, Timerman S. The effects of an online basic life support course on undergraduate nursing students' learning. Int J Med Educ. 2017; 8:309-313 PubMed . doi: 10.5116/ijme.5985.cbce.

20. Greig M, Elliott D, Parboteeah S, Wilks L. Basic life support skill acquisition and retention in student nurses undertaking a pre-registration diploma in higher education/nursing course. Nurse Education Today. 1996; $16(1): 28-31$.

21. Hernandez-Padilla JM, Suthers F, Granero-Molina J, Ferpá Corf frursing students' acquisition and retention of BLS/ AED skills: A Cluster randomised trial. Resuscitation. 2015; 93:27-34.

22. Lindsey PL, Jenkins S. Nursing students' clinical judgment regarding rapid response: the influence of a clinical simulation education intervention. Nursing Forum. 2013; 48(1):61-70. doi: 10.1111/nuf.12002.

23. Kardong-Edgren S, Oermann MH, Odom-Maryon T. Findings from a nursing student CPR study: implications for staff development educators. Journal for Nurses in Staff Development. 2012; 28(1):9-15.

24. Montgomery C, Kardong-Edgren SE, Oermann $\mathrm{MH}$, Odom-Maryon T. Student satisfaction and self-report of CPR competency: HeartCode BLS courses, instructor-led CPR courses, and monthly voice advisory manikin practice for CPR skill maintenance. International Journal of Nursing Education Scholarship. 2012; 3:9. pii: /j/ ijnes.2012.9.issue-1/1548-923X.2361/1548-923X.2361. xml. doi: 10.1515/1548-923X.2361. 